\title{
COEFICIENTES TÉCNICOS DE PRODUÇÃO DE SEMENTES DE CEBOLA NO SUB-MÉDIO SÃO FRANCISCO ${ }^{1}$
}

\author{
CARLOS A. P. ARAGÃO ${ }^{2}$ \\ PAULO A. A. AGUIAR e MOACIR A. DA SILVA ${ }^{3}$
}

RESUmo. A produção de sementes de cebola no Nordeste tem sido avaliada em caráter experimentável através da vernalização artificial dos bulbos e plantio em regiões de microclimas de altitude, onde as temperaturas amenas favorecem o florescimento. A idéia da utilização da região do Sub-Médio São Francisco para produção de sementes de cebola era considerada inviável do ponto de vista prático, já que mesmo com a frigorificação dos bulbos haveria o problema de devernalização, devido às altas temperaturas atingidas sob condições de campo. No presente estudo foram avaliados os coeficientes técnicos de produção de sementes de cebola, cultivar Composto Baia, nas condições climáticas do trópico semi-árido, utilizando-se o sistema de vernalização dos bulbos antes do plantio. A avaliação feita em escala comercial, utilizando-se dois sistemas de irrigação - aspersão e sulcos de infiltração - mostra o potencial de produção de sementes da região, permitindo assim uma utilização mais racional da infraestrutura de irrigação e das condições climáticas de semi-aridez, propícia à obtenção de sementes de alta qualidade.

Termos para indexação: sementes de cebola, produção, vernalização, região do trópico semi-árido, vale do rio São Francisco.

ABSTRACT. Technical coeficients of onion seed production in sub-médio São Franciscos River.

Onion seed production in the northeast Brazil has been tested under experimental conditions by using artificially vernalized bulbs planted under microclimates of altitude where the low temperatures promotes desirable flowering. The idea of using the Sub-Médio São Francisco region for onion seed production has not been considered viable, since even with vernalization of the bulbs, high temperature reached under field conditions could revert the vernalization effect.

1 Trabalho apresentado no I. Congresso Brasileiro de Sementes, Curitiba, Pr., de 26/11 a $02 / 12 / 1979$.

2 Eng. ${ }^{\circ}$ Agr. ${ }^{\circ}$, Técnico da CODEVASF - 3. ${ }^{a}$ Diretoria Regional, Petrolina - PE.

3 Eng. $^{\text {os }}$ Agr. ${ }^{\text {OS }}$ Pesquisadores do CPATSA/EMBRAPA. MS e Ph.D em Tecnologia de Sementes e MS em Irrigação, respectivamente. Petrolina - PE. 
In the present studiy, the technical coefficients of onion seed production, cultivar Composto Baia, were evaluated, under the semi-arid tropics conditions by using the vernalization system of the bulbs before planting. The results obtained under commercial scale indicate the potentiality for onion seed production under two irrigation systems - sprinkler and furrow. Onion seed production would allow a rational utilization of the existing irrigation system as well as of the suitable dry climate essential to obtain high quality seeds.

Index terms: onion seed, production, vernalization, semi-arid tropical region, San Francisco river valley.

\section{INTRODUÇÃO}

A cebola (Allium cepa L.) é uma planta bianual que exige dias longos e temperaturas elevadas para a produção dos bulbos e temperaturas baixas para a diferenciação das gemas florais e conseqüente produção de sementes (Fao, 1961). Estudos indicam que a temperatura responsável pelo estímulo necessário à emissão dos primórdios florais varia entre 6 e $14^{\circ} \mathrm{C}$, estando o ponto ótimo entre 8 e $12^{\circ} \mathrm{C}$, (Hawthorn \&Pollard, 1954; USDA, 1961; Maluf, 1975).

A possibilidade da utilização dos perímetros irrigados do Sub-Médio São Francisco para a produção de sementes de cebola era considerada inviável do ponto de vista prático, já que mesmo com a vernalização artificial dos bulbos haveria o problema de devernalização devido às altas temperaturas atingidas sob condições de campo. Daí porque trabalhos anteriores conduzidos pelo IPA-Pernambuco, utilizavam os microclimas de altitude dos municípios de Garanhus e Triunfo, ou então os bulbos eram remetidos para o Rio Grande do Sul para a produção de sementes (Brasil. SUDENE, 1973).

$\mathrm{Na}$ tentativa de evitar importações maciças do exterior, bem como suprir as deficiências registradas na produção nacional de sementes, em face das constantes incidências de doenças e flutuações climáticas da região Sul, procurou-se avaliar o potencial da região do Sub-Médio São Francisco para a produção de sementes de cebola em escala comercial.

\section{MATERIAL E MÉTODOS}

Avaliou-se na Estação Experimental de Bebedouro em Petrolina, Pernambuco os coeficientes técnicos de produção de sementes de cebola, cultivar Composto Baia, utilizando-se dois sistemas de irrigação: aspersão e sulcos em plantios comerciais de 0,93 e 0,90 hectares, respectivamente. A Estação Experimental fica situada a $09^{\circ} 09^{\prime} \mathrm{S}$ e $40^{\circ} 22^{\prime} \mathrm{W}$, com altitude de $365,5 \mathrm{~m}$, apresenta temperatura mé- 
dia anual de $26,3^{\circ} \mathrm{C}$, umidade relativa média anual de $61,0 \%$ e uma precipitação anual de $605,1 \mathrm{~mm}$, concentrada no período de novembro a abril.

$O$ plantio foi realizado num oxisol de textura arenosa de baix a fertilidade, no espaçamento de $0,50 \mathrm{~m}$ (aspersão) e $0,60 \mathrm{~m}$ (sulcos) fileiras e $15 \mathrm{~cm}$ entre bulbos. A adubação constou de $15 \mathrm{t} / \mathrm{ha}$ de esterco, associada a uma adubação química de 40-60-80 em fundação. Em cobertura aplicou-se 60-0-0 de sulfato de amônio em duas etapas. Antes do plantio os bulbos utilizados foram armazenados em câmara fria a $2 .{ }^{\circ} \mathrm{C}$ durante 3 meses, elevando-se posteriormente a temperatura para $8^{\circ} \mathrm{C}$ por 1 mês para que houvesse o estímulo à floração (vernalização).

$\mathrm{O}$ controle de ervas daninhas foi feito através da combinação de Oxadiazon (Ronstar) e Prometrine (Gesagard) nas doses de 4,8 litros e $300 \mathrm{~g}$ por hectare do produto comercial respectivo. Foi realizado um controle fitossanitário sistemático durante o ciclo da cultura apenas em caráter preventivo.

Como praticamente não houve diferença entre os coeficientes técnicos nos dois sistemas de irrigação,serão apresentados apenas os valores médios correspondentes.

\section{RESULTADOS E DISCUSSÃO}

Coeficientes técnicos:

- Época de plantio: Junho/79.

- Início da floração: Julho (30 dias).

- Peso médio do bulbo: $86 \mathrm{~g}$.

- $\%$ de florescimento: $55 \%$.

- N. ${ }^{\circ}$ médio de umbelas/plantas: 0,90.

- Peso de 100 sementes: 0,35 g.

- $\%$ de sementes $/ \mathrm{kg}$ de bulbos: $3,9 \%$.

- Produção de sementes/planta: 4,50 g.

- Ciclo de produção : 100 dias.

- \% de sobrevivência dos bulbos: $40 \%$.

- Quantidade de bulbos plantados: $7666 \mathrm{~kg} / \mathrm{ha}$.

- Germinação da semente produzida: $90 \%$.

- Produção de semente: $299 \mathrm{~kg} / \mathrm{ha}$.

Muitas hipóteses surgiram nesta etapa preliminar que poderão ser testadas através de pesquisa e incorporadas posteriormente ao processo produtivo. $\mathrm{O}$ baixo índice de florescimento registrado provavelmente poderá ser elevado quando se dispuser de informações mais precisas sobre o tempo ideal de vernalização dos bulbos. 
Constatou-se que o número de umbelas e a produção de sementes por planta foram baixos se comparados com os resultados citados por Hawthorn \& Pollard, 1954. A taxa de $40 \%$ de sobrevivência dos bulbos é também um ponto que atribuise a um manejo inadequado durante a vernalização e operação de plantio. Além dos aspectos mencionados, acredita-se ainda que o baixo peso médio do bulbo e a fertilidade do solo tenham contribuído também para mascarar o real potencial de produção de sementes de cebola da região.

Pelos coeficientes técnicos apresentados constata-se a possibilidade de produção de sementes de cebola na região do Sub-Médio São Francisco. A introdução de inovações técnicas poderá elevar ainda mais este potencial produtivo.

\section{REFERENNCIAS}

BRASIL. SUDENE. 1973. Projeto cebola. Recife. SUDENE, BRASCAN/NE, IPA, ESALQ. Série Projetos de Pesquisa N. ${ }^{\circ}$ 2. 10 p.

FAO, 1961. Las semillas agricolas y horticolas. Roma. Estudios Agropecuários. N. ${ }^{\circ}$ 55. 616 p.

HANTHORN, L.R.; POLLARD, L. H.. 1954. Vegetable and flower seed production. The Blakiston Company, Inc. New York. Toronto. 626 p.

MALUF, W.R. 1975. Produção de sementes de cebola (Allium cepa L.). ESALQ. Piracicaba. São Paulo (Mimeografado) $43 \mathrm{p}$.

USDA, 1961. Seeds. The yearbook of Agriculture. Washington, D.C. 591 p. 